\title{
The Application of Information Technology in English Education and Reform
}

\author{
Xiao Yan ${ }^{1, \mathrm{a}}$, Wang Xiaoge $\mathrm{e}^{1, \mathrm{~b}}$ \\ ${ }^{1}$ Qingdao Huanghai University \\ Qingdao, China \\ a290357329@qq.com, b295038069@qq.com
}

\begin{abstract}
Under the guidance of constructivism theory, information technology provides a good learning environment for College English teaching, so that students can establish truly dominant position, make the independent learning and collaborative learning. The purpose for the application of information is to realize the lifelong education and learning society possible, which has greatly effects to students' learning motivation, cultivate innovation and practice ability. The integration of information technology and College English curriculum cannot stay at the tool level. Teachers should explore the teaching design and teaching strategies in order to form a teaching model, combine teaching theory and practice to promote the thorough reform of English teaching.
\end{abstract}

Keywords-Information technology; English; Education; Reform

\section{INTRODUCTION}

The implementation of information technology education is the primary problem in modern English education. From the overall situation of international, information technology in College English education implementation basically can be divided into two types. One is to set up the account information technology professional, another is the integration of information technology in English teaching, which also produced the third kinds of implementation form. Although the implementation of information technology curriculum in different countries is different, governments all over the world emphasize the use of information technology as teaching tools and learning tools, and use information technology to strengthen the teaching of teachers and students' learning. With the widespread emphasis on integrating information technology into subject teaching, the trend of independent information technology or similar subjects is gradually enhanced in the corresponding sections [1].

\section{THE SITUATION OF INFORMATION TECHNOLOGY EDUCATION}

\section{A. Major educational policy}

Our country has made a series of efforts and adjustments in the educational system and policy. Especially in the course of information technology teachers team building has made great efforts. Improving the survival and development of information technology teachers is an important part of strengthening the construction of information technology teachers, and governments at all levels have attached great importance to it. As the pioneer and leader of English education, the survival and development of information technology teachers determine the development process of educational modernization to a certain extent.

Located in the underdeveloped areas of Western China, the economy and culture are backward, and people's ideas lag behind. Although the quality education has been promoted and implemented in China, the influence of examination oriented education has been deeply rooted. The position of information technology teachers in schools and other subject teachers is generally low. As a practitioner of information technology, the position of information technology in English teaching has a direct impact on the survival and development of the information technology, and affects the improvement of the quality of education and the realization of the teaching objectives.

\section{B. Maintaining the Integrity of the Specifications}

Integration is not simply the superposition of information technology as a means of teaching and traditional teaching methods. It refers to the integration of disciplines (including the branches within each discipline), namely, learning from each other. In the process of integration, the elements of curriculum form organic connection and organic structure. Instead of adding different subjects together, it regards the curriculum as a whole and integrates the knowledge of different disciplines, so that students can master different knowledge unconsciously and organically in the process of learning so as to improve their comprehensive quality [2] Curriculum integration emphasizes the connection and consistency between different disciplines, and avoids premature or overemphasis on the boundaries between different disciplines so as to prevent isolation, repetition or disconnection between different fields. As some educators 
abroad have pointed out, curriculum integration refers to the special effort that links each part of the learning plan that is

\section{CONSTRUCTIVIST LEARNING THEORY AND LEARNING ENVIRONMENT}

English is the most important communication tool, and it is an important part of human culture. English class is a comprehensive tool course, and it is a very practical course [3]. As a basic subject, its teaching contents are reading, writing and oral communication. In the era of information technology, English teaching must have new features.

\section{A. Importance of education reform}

From the perspective of future education, Professor Ceng Xiangqin, President of China reading society, puts forward three methods of reading from three aspects of depth, breadth and speed of reading. What is more, the intensive reading, quick reading should be highly valued.

With the exchange of information between electronic systems as an important means of communication between people, writing teaching will be faced with changes as follows: the status of literature will be reduced, practical writing will become the main style of students learning, and adaptation of relevant information will become an important writing ability.

\section{B. Construction of learning method}

Oral communication skills will be considered as one of the main skills to acquire and maintain a career. The more you want to get a high position, the more you have to learn how to communicate with people of different regions, languages and races.

Constructivist learning theory and learning environment emphasizes student-centered, active construction requires students to transfer from passive recipients of external stimuli and knowledge object subject, information processing knowledge, constructivist teaching theory requires teachers to change from knowledge, students to active construction of meaning help facilitators; requires teachers should adopt in the teaching process, teaching methods and teaching mode of ideological education, and new teaching design.

\section{SPECIFIC IMPLEMENTATION CONTENT}

The information technology and the college English curriculum can be integrated in reading, writing, oral communication, greatly stimulate the learning motivation and autonomous learning, exploratory learning, collaborative learning, and provide strong guarantee for English distance education and lifelong education, such as reading teaching resources more abundant, more effective case, process more in line with the law of thinking of human beings, so it can be economically and effectively achieved. In order to provide more material for the writing teaching, more quickly and more channels is needed to achieve more effective way with the network. For the voice software, it can easily achieve the communication between students and school experts, learning partners for extensive exchanges and providing a broad space for development. closely related.

\section{A. Constructivism learning theory}

In the context creation of constructivism learning theory, it emphasizes the creation of real situations as real as possible, because the real situation is close to the students' life experience. The authenticity of the task enables students to understand the problems they have to solve and have a sense of ownership. The authenticity of the task itself is also easy to inspire students to learn the internal motivation. Situational diversity can cultivate students' exploration spirit, and can express their knowledge in the process of completing tasks [4]. Good situation is an important means to improve the teaching effect, but the effect of teaching by teachers and students, the media and many other factors, creating a situation only after all means of teaching, so in the context of creation to consider various factors, especially the objective reality, to consider whether to create special situations.

\section{B. Make use of resources and explore independently}

The students gain knowledge in the classroom, not only in the preliminary stage of cognition understanding. The teacher should guide the students to use the newly established knowledge and use of cyber source to actively expand and extend the scope of inquiry. The scientific inquiry activities become part of the daily life of students willing to engage in work, enable students to understand not know at school things, and grasp in the textbooks while some students do not have the skills, development in practice, so need to obtain a lot of knowledge for forming ability.

\section{Scientific exploration of virtual experiment}

During the scientific exploration of virtual experiment, teachers should bring into full play the advantage of multimedia teaching, make the teaching content into courseware, make the imagination environment, and produce the realistic feeling. In this way, students feel that they really exist in the virtual environment, and they are part of the environment, not its bystanders. Students are free to interact with relevant virtual situations or events in the environment, as in the real world, understand and grasp the relevant content, and be able to creatively apply and explore the sublimation of English language knowledge in different environments.

\section{Network communication}

Through learning, the students should master the corresponding modern science and technology knowledge, and can use the network communication tools for consultation and communication, cooperative discussion type of learning, make teaching personalized.

The meaning of language is not constant. In our interactions with others, we constantly understand and update the meaning of language. The difference of cultural background leads to the difference of language meaning. The process of transforming thought into language is very important for stimulating all round development. Only through the interaction between the knowledge provided by various vectors and the understanding of students' language, can his knowledge structure be renewed. 


\section{E. Creative practice}

The use of text processing, image processing can be finished by information integration of digital tools. Restructuring and creation of knowledge is applied for curriculum content, so the integration of information technology and curriculum not only impart knowledge to students, let students get knowledge, but also can make the students' knowledge reconstruction and creation.

Using information technology to learn the environment and resources provides the opportunity for learners to self-evaluate feedback. Learning feedback is obtained through formative exercises and works evaluation, and the starting point and path of learning are adjusted.

\section{INTEGRATED MODEL IN ENGLISH TEACHING}

On the training system of knowledge system and ability of traditional English teaching, the teaching of grammar and vocabulary knowledge need to be focused on. A few words included language textbooks only imparting knowledge as the model English teaching, attaching importance to the cultivation of creative thinking, which can pay great attention to the accumulation of insights and influence. It need to be noticed that the meaning of the mode is importance of English culture and language use ability, pay attention to students' practice, let students active learning and exploration in the teaching process

\section{A. The task of integration}

Under the mode of integration, teachers and students carry out teaching and learning with the help of information technology respectively. First of all, teachers analyze and process the teaching materials according to the teaching objectives, decide what forms to show what the teaching content, and in the form of courseware or web page to the students. Students receive the learning task, under the guidance of teachers, the use of information provided by teachers (or their own information), individualized and collaborative combination of autonomous learning, and the use of information technology to complete the task. Finally, teachers and students will study evaluation and feedback together. In the whole process of teaching, students' subjectivity and individualization are greatly reflected. Such a teaching atmosphere is very conducive to the cultivation of students' innovative spirit and problem-solving ability. Similarly, teachers play their leading role by integrating tasks, helping students learn in various forms and ways, and further mobilizing students' learning enthusiasm.

\section{B. Pursuit of teaching mode}

According to the nature of English subject and specific teaching content, teachers and students convert the teaching content into various forms of valuable problems, and present them on the network, and set the logical starting point for the students to study in and out of class.

\section{Inquiry into teaching process}

The students get the related information collated by the teachers compiled and placed on the network and other network information actively [5]. After obtaining basic knowledge in the classroom teaching, on issues related to selfinquiry or collective discussion, teachers need guide students to participate in the discussion and equal attitude, make the teaching process of the transformation from tradition the traditional for inquiry.

\section{Network of teaching activities}

In the teaching activities, changing the past teaching content mainly comes from the single situation of textbooks, emphasizing the ability of students to obtain materials from the network resources, self-reform, reorganization, and create teaching content. What is more, it will develop students' ability and habit to obtain resources from the network.

\section{E. Innovation of teaching results}

The aim of the reform of teaching mode is to cultivate students' innovative spirit. Due to the above reform, the students' subjective status can be truly established, and their autonomy, initiative and cooperation can be brought into full play, which is beneficial to the cultivation of students' innovative consciousness, innovative thinking and innovative personality.

\section{THE MANIFESTATION OF TEACHING MODE}

Traditional teaching attaches great importance to the intensive reading of text, and it cannot be ignored in the network environment, because intensive reading can strengthen students' basic reading ability. In this reading, it emphasizes the overall perception and deep thinking of the text, teachers can provide relevant resources for students and exercise on the spot to read the effect of detection, make instant evaluation by the computer.

\section{A. Thematic reading}

Thematic reading refers to the students read a large number of relevant texts according to certain topics, according to the point round information transmission path. This reading theme is rich, flexible, large information capacity, wide extension, and the transmission path is radiant. Teachers can provide a large number of collated resources, students can obtain relevant resources from the Internet, and you can exchange views in the forum.

\section{B. Selective learning}

In order to learning English more effectively, the students should Learn subjects or read online quickly, and then select the most useful articles or paragraphs for intensive reading according to their needs. This is a kind of information input method from "face" and "point". The results of selective reading are often expressed through writing.

The debate contest moves to the Internet in a written form. This short but tit for tat writing makes thinking constantly colliding and can effectively train students' thinking quality. 
Students get the reading materials from the Internet independently, and after reading, they absorb and create writing according to their own choice and thinking, so that their reading ability, writing ability and information literacy can be improved together.

\section{Integration of reading teaching and information technology}

Let the students learn to read from an article systematically, summarized selection and understanding need to treat as importance. There is a certain degree of difficulty for most students, but to provide a wealth of information resources and update all kinds of knowledge of information technology, let students freely roam in the ocean of knowledge.

Under the guidance of teachers' reading method, students can read independently, which can be independently studied according to the words explanation, article translation, thought analysis, artistic characteristics comparison provided by the network, and also can be read through the beginning of the Flash courseware [6].

\section{The integration of composition teaching and information technology}

When students write an English composition, often have nothing to say, nothing to write, or have it but don't know how to express, even write a few words, did not write a complete sentence successfully. In order to make students have words, you can say it and write it out.

With full use of multimedia technology, students can develop the image of thinking and abstract thinking ability. Composition teaching and information technology integration, one of the commonly used form is to talk, write words. To speak and write a picture is to use a picture and a paragraph of words, let the students write down their knowledge, feelings and imagination, help students realize the psychological conversion from picture to text, and cooperate with the first year of listening and speaking training, the implementation of progressive teaching composition. Students can improvise or take pictures in class, after class, at home and in the wild. Some students scan the picture into the computer with a scanner and store them. Facing the picture and imagining it, it is easy to form a good discourse.

\section{CONCLUSIONS}

Although information technology is our current emphasis, we must be aware of its limitations. The relationship between information technology and traditional media is "symbiosis" rather than "substitutability". In order to give full play to the "moderate role" of information technology in teaching, the integration of information technology and English Teaching in a variety of ways, such as learning, practice, reflection, relearning, re-practice, re-reflection of this cycle process is inevitable path.

\section{REFERENCES}

[1] Hong-Nam K, Leavell A G. "Language learning strategy use of ESL students in an intensive English learning context". System, 2006, pp.399-415.

[2] Hsu M H. "A personalized English learning recommender system for ESL students”. Expert Systems with Applications, 2008, pp.683-688.

[3] Liu G Z, Liu Z H, Hwang G J. "Developing multi-dimensional evaluation criteria for English learning websites with university students and professors". Computers \& Education, 2011, pp.65-79.

[4] Liao P. EFL. "Learners' Beliefs about and Strategy Use of Translation in English Learning.". Relc Journal A Journal of Language Teaching \& Research, 2006, pp.191-215.

[5] Yang J C, Chen C H, Ming C J. "Integrating video-capture virtual reality technology into a physically interactive learning environment for English learning”. Computers \& Education, 2010, pp.1346-1356.

[6] Wang X F, Davies M, Liu G H. "A Good Platform for English Teachers and Learners:the Corpus of Contemporary American English (COCA)". Computer-Assisted Foreign Language Education in China, 2008, pp.215-218. 